\title{
Knowledge about Acute Myocardial Infarction (AMI) and attitudes to medical care seeking-A comparison between patients and the general public
}

\author{
Catrin Henriksson ${ }^{1}$, Margareta Larsson ${ }^{2}$, Judy Arnetz ${ }^{3,4}$, Johan Herlitz ${ }^{5,6}$, Jan-Erik Karlsson ${ }^{7}$, \\ Leif Svensson $^{8}$, Marie Thuresson ${ }^{9}$, Crister Zedigh ${ }^{10}$, Lisa Wernroth ${ }^{1}$, Bertil Lindahl ${ }^{1}$ \\ ${ }^{1}$ Department of Medical Sciences and Uppsala Clinical Research Center, Uppsala University, Uppsala, Sweden \\ ${ }^{2}$ Department of Women's and Children's Health, Uppsala University, Uppsala, Sweden \\ ${ }^{3}$ Department of Family Medicine and Public Health Sciences, Wayne State University, Detroit, USA \\ ${ }^{4}$ Department of Public Health and Caring Sciences, Uppsala University, Uppsala, Sweden \\ ${ }^{5}$ The Center of Prehospital Research in Western Sweden, University of Borås, Borås, Sweden \\ ${ }^{6}$ Institution of Medicine, Sahlgrenska University Hospital, Gothenburg, Sweden \\ ${ }^{7}$ Department of Cardiology, Ryhov Hospital, Jönköping, Sweden \\ ${ }^{8}$ Department of Clinical Science and Education, Karolinska Institute, Stockholm, Sweden \\ ${ }^{9}$ Department of Cardiology, Örebro University Hospital, Örebro, Sweden \\ ${ }^{10}$ Department of Cardiology, Falu Hospital, Falun, Sweden \\ Email: catrin.henriksson@ucr.uu.se
}

Received 2 September 2012; revised 26 October 2012; accepted 13 November 2012

\begin{abstract}
Background: Patients with acute myocardial infarction often have long decision times before seeking medical care. The decision time is influenced by knowledge of AMI-symptoms, psychological factors and the response of people near the patient to the symptoms. Aim: To investigate and compare the knowledge of AMI, intended actions in response to AMI-symptoms and attitudes toward seeking medical care of patients and the general public. Method: This was a multicentre study with descriptive and comparative design, using questionnaires as an instrument. The population consisted of AMI-patients and representatives of the general public. Results: There was good knowledge about typical AMI-symptoms among the participants. The majority thought an AMI always starts suddenly. Patients did not know more about the timedependency of treatment outcome than the general public. A greater proportion of the general public would contact an additional person before consulting medical professionals. Conclusions: Patients had no better knowledge about AMI than the general public, but would more commonly act appropriately in case of AMI-symptoms.
\end{abstract}

Keywords: Acute Myocardial Infarction; Decision Making; Patient; General Public; Knowledge and Attitudes

\section{INTRODUCTION}

Patients with an acute myocardial infarction (AMI) often delay for hours before consulting medical care $[1,2]$. Of the total pre-hospital delay time, over half is related to the patient $[3,4]$.

The best effect of reperfusion treatment is when given within two hours [5,6], but to benefit from treatment patients have to seek medical care sooner. Informational interventions aimed at decreasing patient delay time have generally failed to show long-term results $[7,8]$.

People in general often know about chest pain as a symptom of an AMI [9], but commonly fail to recognise other warning signs $[9,10]$. Knowledge of AMI-symptoms is associated with seeking medical care more promptly [11,12]. Patients usually interpret their symptoms as less serious and not warranting to call for an ambulance $[13,14]$. Attitudes and opinions of other people also influence the decision time [15-17], as do psychological factors $[18,19]$.

When comparing patients and relatives, no large differences in knowledge of AMI or attitudes toward seeking medical care are apparent [20]. However, studies comparing AMI-patients' and the general publics' knowledge of AMI and their intended actions and attitudes in the case of an AMI are generally lacking. Before designing an improved information and education aiming to decrease AMI patients delay time it is important to know how knowledgeable patients and people in general are, and if there are any differences in knowledge between 
the groups. Therefore, the purpose of the present study was to investigate if there were any differences in patients' and the general publics' knowledge of AMI, their intended action in case of AMI-symptoms, and attitudes toward seeking medical care.

\section{METHODS}

\subsection{Design}

This was a multi-centre study with a descriptive and comparative design.

\subsection{Population}

Patients were recruited from cardiology departments of four Swedish hospitals. Inclusion criteria were: $\leq 75$ years old, discharged with the diagnosis of AMI within the last year, and living within the hospitals' catchment areas. The population representing the general public had no prior experience of an AMI and was matched with the patients regarding age, gender and catchment area.

\subsection{Instrument}

The questionnaire was developed by the investigators and used in a previous report [20], the formulation of questions and statements was guided by a previous quailtative study [16]. The questionnaire contained 107 questions for the patient group, and 88 for the general public.

Fifteen questions covered background factors such as age, gender, education, and cardiovascular risk factors. Fourteen questions explored the patients experienced symptoms, and five questions concerned experiences of the patients' medical care seeking process (excluded in the general publics' questionnaire): These questions used force-choice response alternatives. Knowledge questions encompassed risk factors for having an AMI (four questions, data not shown), possible symptoms (nine questions), ambulance equipment (five questions, data not shown), and four statements regarding AMI. The attitude questions contained statements about intended action in case of a suspected AMI, attitudes toward seeking medical care in case of own AMI-symptoms or if someone else experienced symptoms (34 items). Knowledge and attitude questions used a visual analogue scale (VAS) with the end-points (1) "Do not agree at all" to (5) "Agree". When processing the results the scale was divided into 9 steps $(1,1.5,2, \ldots, 4.5,5)$.

The questionnaire also contained 16 statements of the participants intended action in the case of experiencing an arm fracture: These questions were developed as a validity test of the questionnaire, as answers were expected to differ from answers related to a suspected AMI.

The final question examined the satisfaction of given information at hospital (only for the patient group).

\subsection{Procedure}

The study used a subset of a population from a previous investigation [20] in six Swedish hospitals: Patients from two of these hospitals were excluded. The sample size from the remaining four hospitals and their catchment areas was estimated as sufficient. This was based on the statistical calculation that in an incidence of $50 \%$ of a specific variable, the "true" frequency of this variable in the population will be in the interval between $42 \%-58 \%$ with a $95 \%$ probability, and at an incidence of $10 \%$, a similar 95\% confidence interval will be $6.3 \%-13.7 \%$.

A nurse from each of two university and two provincial hospitals used the "Register of Information and Knowledge about Swedish Heart Intensive Care Admissions" (RIKS-HIA) to identify eligible patients according to the inclusion criteria and thereafter a list of patients were sent to the first author.

To identify a representative group of the general public the National Population Registry was used. Three individuals were matched to every patient with respect to age, gender and catchment areas. Thus, at least 75 letters per hospital were distributed in the patient group, including invitation letters, study information and questionnaires: 700 questionnaires were sent to members of the general public. The patients received the questionnaires in August 2006-January 2007, and representatives of the general public received them in April-May 2007. Consent to participation was through returning the completed questionnaire. One reminder was sent after 2 - 4 weeks to non-responders. When the answers were received, all personal identification details were destroyed.

In the patient group, the response rate was $78 \%$ (range $73 \%-82 \%$ ), and in the general public group the response rate was $59 \%$ (range $55 \%-63 \%$ ).

\subsection{Statistics}

The Statistical Package for Social Sciences version 14.0 (SPSS) was used for all statistical analysis. The Chi Square test was used to examine differences between the groups on nominal variables such as background factors. For all ordinal scale variables (knowledge and attitudes), the Mann-Whitney U-test was used. Answers $\geq 3.5$ (range 1 - 5) on the VAS-scale were considered as agreement. For paired comparisons, the Wilcoxon's test was used. In some results, the population was divided into two age groups: $\leq 65$ years and $>65$ years. Due to the multiple comparisons, a p-value of $\leq 0.01$ was chosen as the level of significance.

\subsection{Ethics}

The study was approved by the Regional Medical Ethical Committee in Uppsala. The investigation conformed to the principles outlined in the Declaration of Helsinki. 


\section{RESULTS}

\subsection{Background Characteristics}

The study population consisted of 246 patients and 418 individuals from the general public. The median age and gender distribution was similar in both groups. The general public had more years of education than the patients $(p=0.006)$ and more often lived together with someone $(\mathrm{p}<0.001)$. The general public had fewer risk factors for coronary heart disease (Table 1).

\subsection{Knowledge of AMI}

There were few differences between patients and the general public regarding knowledge of AMI-symptoms. However, patients had better knowledge of symptoms such as abdominal pain and radiating pain in the right arm (Table 2). More than half of all participants believed an AMI always start suddenly; however, the general public more often knew that time is an important factor for treatment outcome in AMI (Table 3).

\subsection{Intended Actions and Attitudes}

The intention to call the alarm number in the case of one's own chest pain was high, but was higher when another person suffered from chest pain. The majority of participants agreed ambulance was the preferable transportation mode when going to hospital because of chest pain. However, the general public to a greater extent than patients preferred to call a taxi. They were also more likely to call the Medical Care Information Service in the case of self-experienced chest pain, and would more commonly contact an additional person before medical professionals. The majority of participants would seek medical care urgently, even for intermittent chest pain. Neither patients nor the general public considered it embarrassing to seek medical care, even if they did not "know" the cause of symptoms (Table 3).

Table 1. Participants background characteristics.

\begin{tabular}{lcc}
\hline \multicolumn{1}{c}{ Characteristics } & $\begin{array}{c}\text { Patients } \\
\mathrm{N}=246 \mathrm{n}(\%)\end{array}$ & $\begin{array}{c}\text { General public } \\
\mathrm{N}=418 \mathrm{n}(\%)\end{array}$ \\
\hline Age, median (min-max) years & $65(31-75)$ & $65(31-76)$ \\
Women & $59(24)$ & $111(27)$ \\
Education $>9$ years & $124(51)$ & $229(61)$ \\
Married/Living together & $152(63)$ & $321(78)$ \\
Smoker/Ex-smoker & $134(54)$ & $161(35)$ \\
Angina pectoris & $79(32)$ & $17(4)$ \\
Treated hypertension & $152(63)$ & $129(31)$ \\
Known diabetes mellitus & $51(21)$ & $28(7)$ \\
Treated hyperlipidemia & $188(78)$ & $63(15)$ \\
Prior PCI/CABG & $246(95)$ & $14(4)$ \\
\hline
\end{tabular}

*(Percutaneous Coronary Intervention) and CABG (Coronary Artery Bypass Grafting) including procedure at present medical care event for the patients.
Table 2. Participants' knowledge of possible AMI-symptoms.

\begin{tabular}{lccc}
\hline Symptoms & $\begin{array}{c}\text { Patients } \\
\mathrm{N}=246 \\
\mathrm{n}(\%)\end{array}$ & $\begin{array}{c}\text { General } \\
\text { public } \\
\mathrm{N}=418 \\
\mathrm{n}(\%)\end{array}$ & p-value $^{*}$ \\
\hline Chest pain/Discomfort & $235(97)$ & $356(98)$ & 0.230 \\
Pain/Discomfort in left arm & $200(84)$ & $307(85)$ & 0.090 \\
Pain/Discomfort in right arm & $113(48)$ & $113(31)$ & $<\mathbf{0 . 0 0 1}$ \\
Back pain & $112(48)$ & $145(41)$ & 0.114 \\
Abdominal pain & $106(45)$ & $112(31)$ & $\mathbf{0 . 0 0 4}$ \\
Nausea & $163(69)$ & $233(65)$ & 0.888 \\
\hline
\end{tabular}

"The Mann Whitney-U test. p-value $\leq 0.01$ for statistical significance.

\subsection{General Public, Gender and Age}

Generally, there were few gender differences, although, women had better knowledge of the symptoms of back pain $(\mathrm{p}<0.001)$, nausea $(\mathrm{p}<0.001)$ and abdominal pain $(\mathrm{p}<0.001)$ than men. Neither men nor women considered waiting for symptoms to disappear before seeking medical care (Table 4).

Age did not affect the frequency of calling the alarm number if experiencing chest pain. More people in the younger age-group ( $\leq 65$ years) would wait before seeking medical care than older individuals (66 - 75 years), and more commonly thought people must be very ill before being taken care of at the Emergency Department (Table 4). Older participants more often believed they would seek medical care urgently in case of own chest pain, even if they did not "know" that the heart caused the symptoms (Table 4).

\subsection{Comparison between Chest Pain and an Arm Fracture}

Participants were asked similar questions regarding chest pain and arm fracture. The answers differed between chest pain and arm fracture $(p<0.001)$ for all statements except two: contacting an additional person in case of own symptoms $(p=0.648)$, and being present when someone else suffered from symptoms $(p=0.957)$.

\section{DISCUSSION}

This study was one of the first to compare AMI-patients and general publics' knowledge of AMI, their intended actions, and attitudes in the medical care seeking process. Some studies have investigated general publics' knowledge about AMI [10,21,22], and one study [23] compares chest pain-patients with community members, but only regarding the intention of calling the alarm number in case of cardiac event.

There were few differences in knowledge between the general public and AMI-patients: The patients were expected to be more knowledgeable, as they had received 
Table 3. Knowledge of AMI, intended actions and attitudes toward seeking medical care in case of an AMI. Proportion of participants' agreement ${ }^{* *}$ to the statements.

\begin{tabular}{|c|c|c|c|}
\hline Variable & $\begin{array}{c}\text { Patients } \\
\mathrm{N}=246 \mathrm{n}(\%)\end{array}$ & $\begin{array}{l}\text { General public } \\
\mathrm{N}=418 \mathrm{n}(\%)\end{array}$ & p-value* \\
\hline An AMI always starts suddenly. & $143(59)$ & $195(52)$ & 0.337 \\
\hline Time is of no importance when it comes it comes to treatment results for AMI. & $23(10)$ & $17(5)$ & 0.003 \\
\hline I would call the alarm number if experiencing own chest pain. & $208(86)$ & $280(75)$ & 0.012 \\
\hline I would call the alarm number if I meet someone experiencing chest pain. & $223(93)$ & $322(85)$ & 0.157 \\
\hline Ambulance transportation to hospital is the best choice in case of chest pain. & $217(91)$ & $330(88)$ & 0.651 \\
\hline I would call a taxi for transportation to the Emergency Department if experiencing own chest pain. & $71(31)$ & $170(46)$ & 0.001 \\
\hline $\begin{array}{l}\text { I would call a taxi for transportation to the Emergency Department if I meet someone experiencing } \\
\text { chest pain. }\end{array}$ & $85(37)$ & $191(51)$ & $<0.001$ \\
\hline I would ask for lift to the Emergency Department if experiencing own chest pain. & $83(36)$ & $156(42)$ & 0.015 \\
\hline If I experience chest pain, I prefer to wait and see if symptoms disappear before going to hospital. & $38(16)$ & $79(22)$ & 0.040 \\
\hline I would contact a further person before medical staff, if I suffered from own chest pain. & $49(21)$ & $144(39)$ & $<0.001$ \\
\hline I would seek medical care urgently, even if chest pain was of intermittent character. & $197(84)$ & $296(80)$ & 0.321 \\
\hline You always have to wait at the Emergency Department, regardless of why you are seeking care. & $34(15)$ & $115(31)$ & $<0.001$ \\
\hline $\begin{array}{l}\text { You have to be very ill in order to be taken care of at the Emergency Department when a } \\
\text { suspected AMI occurs. }\end{array}$ & $34(14)$ & $63(17)$ & 0.087 \\
\hline $\begin{array}{l}\text { I would not seek urgent care if I didn't "know" that it was the heart causing the symptoms. It } \\
\text { would be embarrassing if the symptoms didn't involve any dangerous complaint. }\end{array}$ & $35(15)$ & $46(12)$ & 0.357 \\
\hline It is important to be clean and tidy when going to the Emergency Department. & $50(21)$ & $80(21)$ & 0.379 \\
\hline
\end{tabular}

${ }^{*}$ Mann-Whitney U-test. p-value $\leq 0.01$ for statistical significance. ${ }^{* *}$ Answers $\geq 3.5$ on the VAS-scale were considered as agreement. PCI: Percutanous Coronary Intervention.

Table 4. Knowledge of AMI, intended actions and attitudes toward seeking medical care in case of an AMI. Proportion of the general publics' agreement ${ }^{* *}$ to the statements by gender and age.

\begin{tabular}{|c|c|c|c|c|c|c|}
\hline Variable & $\begin{array}{l}\text { Men } \\
\mathrm{N}=307 \\
\mathrm{n}(\%)\end{array}$ & $\begin{array}{l}\text { Women } \\
\mathrm{N}=111 \\
\mathrm{n}(\%)\end{array}$ & p-value ${ }^{*}$ & $\begin{array}{l}\leq 65 \text { years } \\
\mathrm{N}=236 \\
\mathrm{n}(\%)\end{array}$ & $\begin{array}{l}>65 \text { years } \\
\mathrm{N}=178 \\
\mathrm{n}(\%)\end{array}$ & p-value ${ }^{*}$ \\
\hline I would call the alarm number if experiencing own chest pain. & $203(75)$ & $77(74)$ & 0.434 & $150(69)$ & $130(81)$ & 0.024 \\
\hline $\begin{array}{l}\text { I would call the alarm number if I meet someone experiencing } \\
\text { chest pain. }\end{array}$ & $232(84)$ & $90(86)$ & 0.059 & $178(82)$ & $144(88)$ & 0.171 \\
\hline I think people often use ambulance for insignificant things. & $46(17)$ & $9(9)$ & 0.001 & $35(16)$ & $20(13)$ & 0.012 \\
\hline $\begin{array}{l}\text { If I experience chest pain, I prefer to wait and see if symptoms } \\
\text { disappear before going to hospital }\end{array}$ & $53(20)$ & $26(26)$ & 0.162 & $55(26)$ & $24(16)$ & 0.001 \\
\hline $\begin{array}{l}\text { If I meet someone suffered from chest pain, I prefer to wait } \\
\text { and see if symptoms disappear before going to hospital. }\end{array}$ & $53(20)$ & $26(26)$ & 0.124 & $55(26)$ & $24(16)$ & 0.094 \\
\hline $\begin{array}{l}\text { I would not call for an ambulance because all the attention } \\
\text { would be embarrassing. }\end{array}$ & $34(13)$ & $6(6)$ & 0.056 & $24(11)$ & $16(10)$ & 0.057 \\
\hline $\begin{array}{l}\text { You have to be very ill in order to be taken care of at the } \\
\text { Emergency Department when a suspected AMI occurs. }\end{array}$ & 45 (17) & 18 (18) & 0.841 & $44(21)$ & $19(12)$ & $<0.001$ \\
\hline $\begin{array}{l}\text { I would not seek urgent care if I didn't "know" that it was the } \\
\text { heart causing the symptoms. It would be embarrassing if the } \\
\text { symptoms didn't involve any dangerous complaint. }\end{array}$ & $32(12)$ & $14(14)$ & 0.704 & $28(13)$ & $18(11)$ & $<0.001$ \\
\hline $\begin{array}{l}\text { It is important to be clean and tidy before going to the } \\
\text { Emergency Department. }\end{array}$ & $63(23)$ & $17(16)$ & 0.494 & $34(16)$ & $46(29)$ & 0.193 \\
\hline
\end{tabular}

*Mann-Whitney U-test. p-value $\leq 0.01$ for statistical significance; ${ }^{* *}$ Answers $\geq 3.5$ on the VAS-scale were considered as agreement. 
information from the hospital.

Less than half of all cases of AMI experience chest pain with sudden onset [24], but in the present study more than half of the study population thought an AMI always starts suddenly: This false notion may increase patients' decision time before seeking medical care. Knowledge of AMI-symptoms such as chest pain and radiating pain in the left arm was widespread among the participants, and this result was in accordance with other studies $[10,25]$. However, the participants in the present study were less likely to indicate pain in the right arm, back- and abdominal pain as AMI-symptoms. The traditional symptoms of an AMI are chest pain and radiating pain in the left arm and those symptoms are often mentioned and well-known by the public. The patients' higher awareness of pain in the right arm as an AMI symptom is probably due to their own experience.

People with limited knowledge of AMI-symptoms [11] or unaware of the importance of prompt treatment [26] are more likely to delay seeking medical care. However, the majority of both patients and the general public in this study knew about time-dependency in treatment outcome. Therefore, only lack of knowledge appeared less important in explaining long patient delay-time.

Patients were more likely to act appropriately in seeking medical care than the general public, which could be explained by having received the recommendations during their previous hospital stay.

The majority of participants reported they would call for an ambulance in case of chest pain, but previous investigations indicate that less than half of all AMI-patients arrive at hospital by ambulance $[4,20]$. In agreement with another study [23], few participants considered to drive someone suffering from AMI-symptoms to hospital, but in reality up to $60 \%$ of AMI-patients are driven to hospital by someone instead of using ambulance [23].

Other people often influence patients' decision to seek medical care $[3,15,16]$. In the present study, more members of the general public compared to the patients reported that they would contact an additional person before consulting medical professionals. If the person who was contacted lacked knowledge about how to act, it might be a barrier to a correct decision [27].

Only about $1 / 5$ of the participants reported they would wait before seeking medical care in case of self-experienced chest pain, however, this contradicts what many people tend to do in reality [28-30]. Some explanations for long decision times are denial and underestimation of the severity of the situation $[18,19,31]$. In these cases, the general public might be key-people in influencing quicker decisions.

The female representatives of the general public had better knowledge of the symptoms back pain and nausea:
This concurred with previous studies [10,20]. These symptoms are more common in women [24,32], and it is possible women learn more about them than men do.

Elderly representatives of the general public would more often act appropriately in seeking medical care and may have a more realistic view of the situation and understand the increased risk of having a serious condition [33].

\subsection{Method Discussion and Limitations}

The patient group was limited to AMI-patients entered in the RIKS-HIA register and admitted to a Cardiology Department. Participants were recruited from different geographic areas in Sweden, which increases the possibility of generalising the results. The age limit of 75 years was chosen to decrease the influence of co-morbidities; thus, the results might not be applicable to people $>75$ years. The age limit might influence the gender distribution as women develop AMI at an older age. The questionnaire was developed in Swedish, which limited participation for people with language barriers. The questionnaire was not tested for reliability, but there were discrepancies between intended actions in case of chest pain compared to an arm fracture, which was interpreted as evidence of good reliability. Many questions were straight-forward and easy to understand and the statements were based on previous qualitative interviews, which strengthened the validity of the instrument.

\subsection{Conclusions}

There were generally few differences between the general public and the patients, however patients had no better knowledge of AMI than the general public, but would act more appropriately in seeking medical care for suspected AMI.

Few gender differences were observed in the general public group, but elderly representatives were more likely to act appropriately in case of chest pain than younger participants were.

\subsection{Practice Implications}

Education and information to patients and the general public about appropriate action in case of symptoms suggestive of AMI need to be improved. Individualized information have to be provided, and the rehabilitation programme should include both written and verbal information about typical and atypical symptoms, the advantage of ambulance use, and the importance of receiving prompt treatment. Participants in the rehabilitation programme should discuss common attitudes and actions that delay seeking medical care, and the advantage in cardiac muscle salvage when receiving fast treat- 
ment. Information and education programmes are suggested to be scientifically evaluated before implementation in general use.

\section{ACKNOWLEDGEMENTS}

We would like to thank the nurses at each participating hospital, Karin Johansson, Jens Nilsson and Gunnar Turesson, for identifying patients. We would also thank the Uppsala University Hospital's Development Foundation and the Department of Cardiology in Uppsala for financial contribution.

\section{REFERENCES}

[1] McGinn, A.P., Rosamond, W.D., Goff Jr., D.C., Taylor, H.A., Miles, J.S. and Chambless, L. (2005) Trends in prehospital delay time and use of emergency medical services for acute myocardial infarction: Experience in 4 US communities from 1987-2000. American Heart Journal, 150, 392-400. doi:10.1016/j.ahj.2005.03.064

[2] Boersma, E. (2006) Does time matter? A pooled analysis of randomized clinical trials comparing primary percutaneous coronary intervention and in-hospital fibrinolysis in acute myocardial infarction patients. European Heart Journal, 27, 779-788. doi:10.1093/eurheartj/ehi810

[3] Rasmussen, C.H., Munck, A., Kragstrup, J. and Haghfelt, T. (2003) Patient delay from onset of chest pain suggesting acute coronary syndrome to hospital admission. Scandinavian Cardiovascular Journal, 37, 183-186. doi:10.1080/14017430310014920

[4] Perkins-Porras, L., Whitehead, D.L., Strike, P.C. and Steptoe, A. (2009) Pre-hospital delay in patients with acute coronary syndrome: Factors associated with patient decision time and home-to-hospital delay. European Heart Journal, 8, 26-33. doi:10.1016/j.ejcnurse.2008.05.001

[5] Boersma, E., Maas, A.C., Deckers, J.W. and Simoons, M.L. (1996) Early thrombolytic treatment in acute myocardial infarction: Reappraisal of the golden hour. Lancet, 348, 771-775. doi:10.1016/S0140-6736(96)02514-7

[6] De Luca, G., Suryapranata, H., Ottervanger, J.P. and Antman, E.M. (2004) Time delay to treatment and mortality in primary angioplasty for acute myocardial infarction: Every minute of delay counts. Circulation, 109, 12231225. doi:10.1161/01.CIR.0000121424.76486.20

[7] Kainth, A., Hewitt, A., Sowden, A., Duffy, S., Pattenden, J., Lewin, R., Watt, I. and Thompson, D. (2004) Systematic review of interventions to reduce delay in patients with suspected heart attack. Emergency Medicine Journal, 21, 506-508. doi:10.1136/emj.2003.013276

[8] Luepker, R.V., Raczynski, J.M., Osganian, S., Goldberg, R.J., Finnegan Jr., J.R., Hedges, J.R., Goff Jr., D.C., Eisenberg, M.S., Zapka, J.G., Feldman, H.A., Labarthe, D.R., McGovern, P.G., Cornell, C.E., Proschan, M.A. and Simons-Morton, D.G. (2000) Effect of a community intervention on patient delay and emergency medical service use in acute coronary heart disease: The Rapid Early Action for Coronary Treatment (REACT) Trial. JAMA, 284, 60-67. doi:10.1001/jama.284.1.60
[9] Goff Jr., D.C., Sellers, D.E., McGovern, P.G., Meischke, H., Goldberg, R.J., Bittner, V., Hedges, J.R., Allender, P.S. and Nichaman, M.Z. (1998) Knowledge of heart attack symptoms in a population survey in the United States: The react trial. Rapid early action for coronary treatment. Archives of Internal Medicine, 158, 2329-2338. doi:10.1001/archinte.158.21.2329

[10] Greenlund, K.J., Keenan, N.L., Giles, W.H., Zheng, Z.J., Neff, L.J., Croft, J.B. and Mensah, G.A. (2004) Public recognition of major signs and symptoms of heart attack: Seventeen states and the US Virgin Islands, 2001. American Heart Journal, 147, 1010-1016. doi:10.1016/j.ahj.2003.12.036

[11] Khan, M.S., Jafary, F.H., Faruqui, A.M., Rasool, S.I., Hatcher, J., Chaturvedi, N. and Jafar, T.H. (2007) High prevalence of lack of knowledge of symptoms of acute myocardial infarction in Pakistan and its contribution to delayed presentation to the hospital. BMC Public Health, 7, 284. doi:10.1186/1471-2458-7-284

[12] Ruston, A., Clayton, J. and Calnan, M. (1998) Patients' action during their cardiac event: Qualitative study exploring differences and modifiable factors. $B M J, 316$, 1060-1064. doi:10.1136/bmj.316.7137.1060

[13] Lozzi, L., Carstensen, S., Rasmussen, H. and Nelson, G. (2005) Why do acute myocardial infarction patients not call an ambulance? An interview with patients presenting to hospital with acute myocardial infarction symptoms. Internal Medicine Journal, 35, 668-671.

[14] Johansson, I., Stromberg, A. and Swahn, E. (2004) Ambulance use in patients with acute myocardial infarction. Journal of Cardiovascular Nursing, 19, 5-12.

[15] Thuresson, M., Jarlov, M.B., Lindahl, B., Svensson, L., Zedigh, C. and Herlitz, J. (2007) Thoughts, actions, and factors associated with prehospital delay in patients with acute coronary syndrome. Heart Lung, 36, 398-409. doi:10.1016/j.hrtlng.2007.02.001

[16] Henriksson, C., Lindahl, B. and Larsson, M. (2007) Patients' and relatives' thoughts and actions during and after symptom presentation for an acute myocardial infarction. European Journal of Cardiovascular Nursing, 6, 208206. doi:10.1016/j.ejcnurse.2007.02.001

[17] Alonzo, A.A. (1986) The impact of the family and lay others on care-seeking during life-threatening episodes of suspected coronary artery disease. Social Science \& Medicine, 22, 1297-1311. doi:10.1016/0277-9536(86)90093-6

[18] Perkins-Porras, L., Whitehead, D.L., Strike, P.C. and Steptoe, A. (2008) Causal beliefs, cardiac denial and prehospital delays following the onset of acute coronary syndromes. Journal of Behavioral Medicine, 31, 498-505. doi:10.1007/s10865-008-9174-3

[19] Stenstrom, U., Nilsson, A.K., Stridh, C., Nijm, J., Nyrinder, I., Jonsson, A., Karlsson, J.E. and Jonasson, L. (2000) Denial in patients with a first-time myocardial infarction: Relations to pre-hospital delay and attendance to a cardiac rehabilitation programme. European Journal of Cardiovascular Prevention \& Rehabilitation, 12, 568-571. doi:10.1097/01.hjr.0000186620.75733.15

[20] Henriksson, C., Larsson, M., Arnetz, J., Berglin-Jarlov, 
M., Herlitz, J., Karlsson, J.E., Svensson, L., Thuresson, M., Zedigh, C., Wernroth, L. and Lindahl, B. (2011) Knowledge and attitudes toward seeking medical care for AMIsymptoms. International Journal of Cardiology, 147, 224-227. doi:10.1016/j.ijcard.2009.08.019

[21] Limbu, Y.R., Malla, R., Regmi, S.R., Dahal, R., Nakarmi, H.L., Yonzan, G. and Gartaula, R.P. (2006) Public knowledge of heart attack in a Nepalese population survey. Heart Lung, 35, 164-169. doi:10.1016/j.hrtlng.2005.12.003

[22] Ratner, P.A., Tzianetas, R., Tu, A.W., Johnson, J.L., Mackay, M., Buller, C.E., Rowlands, M. and Reime, B. (2006) Myocardial infarction symptom recognition by the lay public: The role of gender and ethnicity. Journal of Epidemiology \& Community Health, 60, 606-615. doi:10.1136/jech.2005.037952

[23] Brown, A.L., Mann, N.C., Daya, M., Goldberg, R., Meischke, H., Taylor, J., Smith, K., Osganian, S. and Cooper, L. (2000) Demographic, belief, and situational factors influencing the decision to utilize emergency medical services among chest pain patients. Rapid Early Action for Coronary Treatment (REACT) study. Circulation, 102, 173178. doi:10.1161/01.CIR.102.2.173

[24] Thuresson, M., Jarlov, M.B., Lindahl, B., Svensson, L., Zedigh, C. and Herlitz, J. (2005) Symptoms and type of symptom onset in acute coronary syndrome in relation to ST elevation, sex, age, and a history of diabetes. American Heart Journal, 150, 234-242. doi:10.1016/j.ahj.2004.08.035

[25] Goff Jr., D.C., Mitchell, P., Finnegan, J., Pandey, D., Bittner, V., Feldman, H., Meischke, H., Goldberg, R.J., Luepker, R.V., Raczynski, J.M., Cooper, L. and Mann, C. (2004) Knowledge of heart attack symptoms in 20 US communities. Results from the rapid early action for coronary treatment community trial. Preventive Medicine, 38, 8593. doi:10.1016/j.ypmed.2003.09.037

[26] Herlitz, J., Thuresson, M., Svensson, L., Lindqvist, J.,
Lindahl, B., Zedigh, C. and Jarlov, M. (2010) Factors of importance for patients' decision time in acute coronary syndrome. International Journal of Cardiology, 141, 236242. doi:10.1016/j.ijcard.2008.11.176

[27] Glanz Karen, R.B. and Viswanath, K. (2008) Health behavior and health education: Theory, research and practice. Jossey-Bass, San Francisco.

[28] Saczynski, J.S., Yarzebski, J., Lessard, D., Spencer, F.A., Gurwitz, J.H., Gore, J.M. and Goldberg, R.J. (2008) Trends in prehospital delay in patients with acute myocardial infarction (from the Worcester Heart Attack Study). American Journal of Cardiology, 102, 1589-1594. doi:10.1016/j.amjcard.2008.07.056

[29] Floyd, K.C., Yarzebski, J., Spencer, F.A., Lessard, D., Dalen, J.E., Alpert, J.S., Gore, J.M. and Goldberg, R.J. (2009) A 30 -year perspective (1975-2005) into the changing landscape of patients hospitalized with initial acute myocardial infarction: Worcester heart attack study. Circulation: Cardiovascular Quality and Outcomes, 2, 88-95. doi:10.1161/CIRCOUTCOMES.108.811828

[30] Goldberg, R.J., Spencer, F.A., Fox, K.A., Brieger, D., Steg, P.G., Gurfinkel, E., Dedrick, R. and Gore, J.M. (2009) Prehospital delay in patients with acute coronary syndromes (from the Global Registry of Acute Coronary Events [GRACE]). American Journal of Cardiology, 103, 598603. doi:10.1016/j.amjcard.2008.10.038

[31] Leventhal, H. and Cameron, L. (2003) The self-regulation of health and illness behaviour. Routledge, New York.

[32] Lovlien, M., Schei, B. and Hole, T. (2006) Women with myocardial infarction are less likely than men to experience chest symptoms. Scandinavian Cardiovascular Journal, 40, 342-347. doi:10.1080/14017430600913199

[33] Ryan, C.J. and Zerwic, J.J. (2003) Perceptions of symptoms of myocardial infarction related to health care seeking behaviors in the elderly. Journal of Cardiovascular Nursing, 18, 184-196. 